\title{
Detection of Rotor Bar Faults in Field Oriented Controlled Induction Motors
}

\author{
Mehmet Akar ${ }^{\dagger}$ \\ ${ }^{\dagger}$ Dept. of Mechatronics Eng., Gaziosmanpaşa University, Tokat, Turkey
}

\begin{abstract}
In this study, a new method has been presented for the detection of broken rotor bar (BRB) faults in inverter driven induction motors controlled via Field Oriented Control (FOC). To this end, a FOC controlled induction motor with a BRB fault was modeled using the Matlab/Simulink program. Experiments were carried out using the prepared simulation model at various loads and operating speeds. The motor current and speeds were monitored for healthy, 1, 2 and 3 BRB faults. The Resampling Based Order Tracking Analysis (RB-OTA) method was applied to the monitored signals. The obtained results were compared by using the classic Fast Fourier Transform (FFT) method. When the obtained results were analyzed via the FFT method no information regarding any faults was determined in the run up or run down regions of the motor and the presented method gave very good results. The reliability of the proposed method was validated with experimental results. The main innovative part of this study is that the RB-OTA method was implemented on the induction motor current signal for detecting BRB faults.
\end{abstract}

Key words: Broken rotor bar fault, Field oriented control, Induction motor, Resampling based order tracking analysis

\section{INTRODUCTION}

Induction motors are preferred in many industrial applications due to their comparatively simple structures, cheap prices and stable operation. The early detection of faults in the electrical and mechanical parts of these motors is very important in terms of facility safety and costs. As it is the case in all rotating machines, periodic maintenance is very important to ensure that the electrical motors operate without any faults for a long time. Today, real time condition monitoring and predictive maintenance is taking the place of periodic applications. Hence the condition monitoring and predictive maintenance of electric motors have been one of the most important topics in recent years [1]-[7].

Inverter driven induction motors are frequently used in applications that require variable speed and torque. Thanks to developments in control methods and inverter capabilities, induction motors can also be controlled as direct current motors and are frequently preferred in applications that require fast response, speed sensitivity and position control.

One of the methods used for such motors is the Field

Manuscript received Aug. 20, 2011; revised Aug 21, 2012

Recommended for publication by Associate Editor Tae-Woong Kim.

†Corresponding Author: mehmet.akar@gop.edu.tr

Tel: +90-356-2521800, Fax: +90-356-2521729, Gaziosmanpaşa Univ.

Dept. of Mechatronics Eng., Gaziosmanpaşa University, Turkey
Oriented Control (FOC) method. In the FOC method the current, voltage and flux are transferred to 2 planes with a phase difference of $90^{\circ}$ [8]. Hence the speed and torque of the induction motors can be controlled independently just as in a separately excited direct current motor.

Since the voltage applied to the motor windings in inverter driven motors is not pure sinusoidal, additional harmonics are injected to the motor windings. These harmonics may cause an additional temperature rise in the windings along with resonance in the moment generated by the motor. This in turn causes knocking and deviations in the speed of the systems in which these motors are used. With switching frequency in the new generation IGBTs approaching $20 \mathrm{kHz}$, the effects of the aforementioned problems on the motor have been decreased. However, when the amplitudes of the additional harmonics injected into the motor current are large, the harmonics related to the fault are suppressed and this decreases the reliability of the methods used for fault detection [9].

The method that is most widely used for fault detection in induction motors is motor current signal analysis (MCSA). This method is based on the principle of monitoring the frequency components of the monitored signal via FFT analysis. The traditional MCSA method is especially successful for motors operating under a constant load torque, speed and voltage [10]. However, it is insufficient for systems operating under variable loads such as compressors, freight 
lifts, etc. There are many studies in the literature regarding the detection of BRB faults in induction motors via the MCSA method [11]-[18]. In order to detect BRB faults, the researchers have monitored the sideband components that occur in the upper and lower sidebands of the fundamental frequency. However, the motor speed changes continuously in inverter driven motors and this in turn changes both the amplitude and the frequency of the voltage applied to the motor windings and the current passing through the motor windings. The MCSA method, which gives successful results for stationary signals, is insufficient for dynamic signals.

The Resampling Based Order Tracking Analysis (RB-OTA) method has been used successfully for the dynamic signals in the monitoring of rotating machines and predictive maintenance applications [19]. This method is based on the principle of monitoring the dynamic vibration signals and the shaft speed and carrying out resampling of the vibration signal according to the speed signal. Thus the detection of faults related to the rotor speed in systems with variable speeds is successfully carried out [20]-[23].

In this study the RB-OTA method was implemented on motor current and speed signal to detect BRB faults. The RB-OTA method's marking flow diagram is given in Fig. 1 [19]. The RB-OTA method steps are given below:

- Acquire data samples from the encoder and current sensor synchronously at a constant sample rate.

- Determine the pulse edges from the encoder signal and interpolate the pulse edges to get the time instance for resampling.

- Perform software resampling on the current signal according to the time instant determined in step a and generate the angle-samples.

- Obtain the order spectrum of the signal by performing a FFT on the angle-samples.

- Track the magnitude and phase of each individual order for a long time, revolution, or rpm.
This paper is divided into six sections. Following the introd uction, Section 2 presents and discusses an induction motor under a BRB fault. Section 3 introduces RB-OTA and the c orresponding algorithms to obtain an angular domain represe ntation of stationary and non-stationary signals. Simulation a nd experimental models are presented in Section 4. The obt ained results are presented in Section 5, along with the feat ure extraction method by means of the order components o $\mathrm{f}$ the current signal. Finally, conclusions are stated in Sectio n 6 .

\section{INDUCTION MOTOR BROKEN ROTOR BAR FAULTS}

Squirrel cage rotor design and manufacturing have undergone little change over the years [24]. Rotor related faults are usually associated with thermal stresses, magnetic stresses due to electromagnetic forces, residual stresses in insufficient manufacturing and environmental stresses that are caused by moisture, etc [6]. Rotor faults start as a high resistance, causing high temperatures and then progress to cracking or small holes in the rotor bars [25]. These faults are more likely to take place at the cage end rings. Different motor parameters such as pulsations in the speed, air gap flux, vibrations and motor current signature can be monitored for the detection of BRB faults. Early fault detection techniques for these motors can significantly reduce the maintenance costs. Spectrum analysis has been preferred by most researchers. Thomson and Stewart [26], Kliman et al [27], Flippetti et al [28] and Elkasabgy [29] used MCSA to detect broken bar faults. They demonstrated sideband components around the fundamental frequency to detect BRB faults. The lower sideband is for broken bars whereas the upper sideband is for consequent speed oscillations.

$$
f_{b}=(1 \pm 2 k s) f_{0}
$$

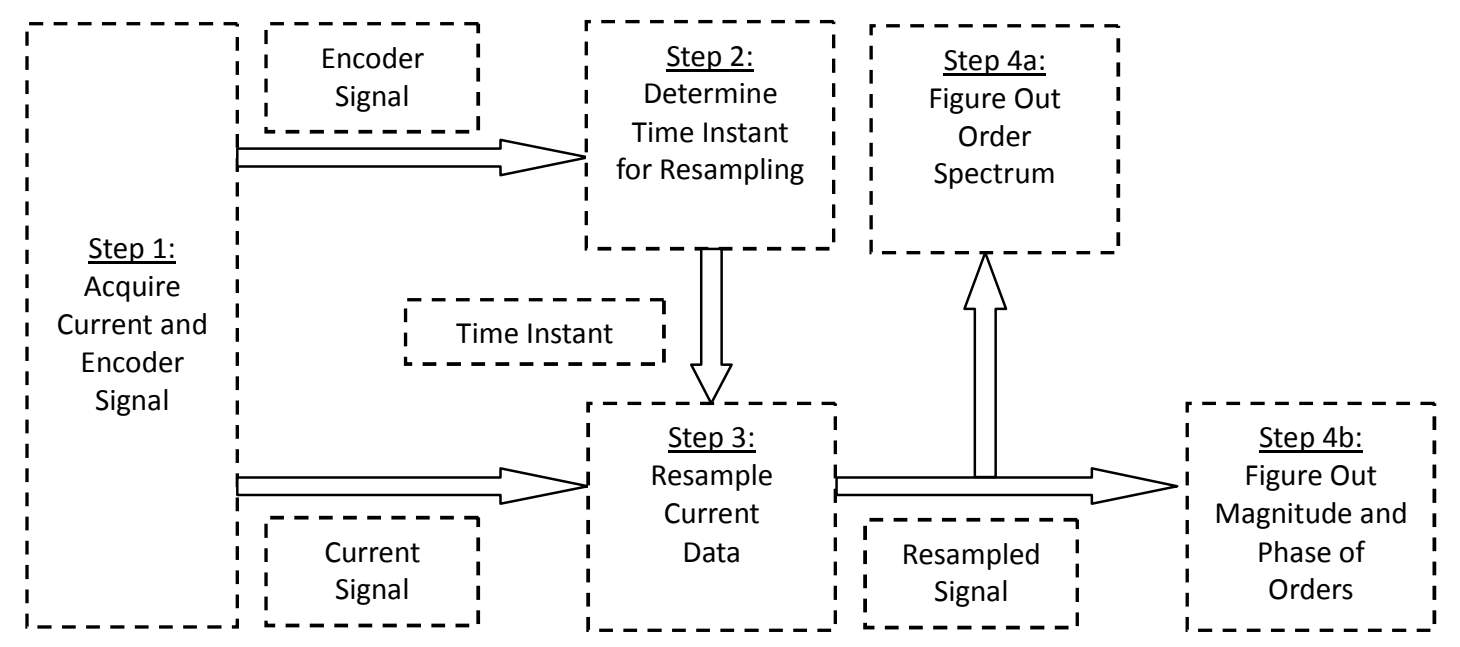

Fig. 1. Resampling Based Order Tracking Analysis Diagram. 
$f_{0}$ is the frequency of the supply phase, $s$ is the motor slip and $\mathrm{k}=0,1,2, \ldots \mathrm{n}$. The magnitudes of the sideband components change with the load inertia. In addition to Equation (1), other spectral components that occur can be observed in the motor line current by using Equation (2) [30].

$$
\left.f_{b}=\left(\left(\frac{k}{p}\right)(1-s) \pm s\right)\right) f_{0}
$$

$p$ denotes the number of pole pairs $(p=2,4, . . n)$. Fig. 2 shows the frequency of the components specific for BRB faults, which is given in Equation 1 for $k=1,2$ and 3. These frequencies are located around the fundamental line frequency and are called lower sideband and upper sideband components, as indicated in Fig. 2 [31].

\section{A. Mathematical Model of Induction Machines with Broken \\ Rotor Bars Faults}

In induction motors, the air gap between the stator and the rotor is symmetrically distributed [32]. A fault that occurs in these motors causes a disruption of this symmetry. The BRB faults in induction motors causes a change in the rotor phase resistances and instability between the rotor phases which in turn results in a disruption of the symmetry in the rotating electromagnetic field between the stator and the rotor. As a result, this asymmetrical situation produces additional frequency components in the motor currents. Thus the modeling of BRB faults in the mathematical modeling of induction motors can be easily carried out by additional resistances added to the rotor phase resistances [32].

In the modeling study that was carried out, the effect of the rotor end ring was neglected and it was assumed that the resistance and inductance of the stator did not change. In this case, the modified rotor resistance matrix in the abc reference domain can be written as in Equation (3) [32].

$$
r_{r}^{*}=\left[\begin{array}{ccc}
\left(r_{r}+\Delta r_{r a}\right) & 0 & 0 \\
0 & \left(r_{r}+\Delta r_{r b}\right) & 0 \\
0 & 0 & \left(r_{r}+\Delta r_{r c}\right)
\end{array}\right]
$$

The $\Delta r_{r a}, \Delta r_{r b}, \Delta r_{r c}$ expressions in the equality represent the changes in the rotor resistance arising from the BRB faults in phases $a, b$ and respectively. The given in Equation (3) can be defined as below [32].

$$
\Delta r_{r a, b, c}=\frac{3 n_{b b}}{N_{b}-3 n_{b b}} r_{r}
$$

The expressions of, , represent the number of faulty rotor bars, the total number of rotor bars and the rotor one phase equivalent resistance, respectively. When the effect of the end ring is neglected, the rotor one phase equivalent resistance for a healthy induction motor can be expressed as in Equation (5) [32].

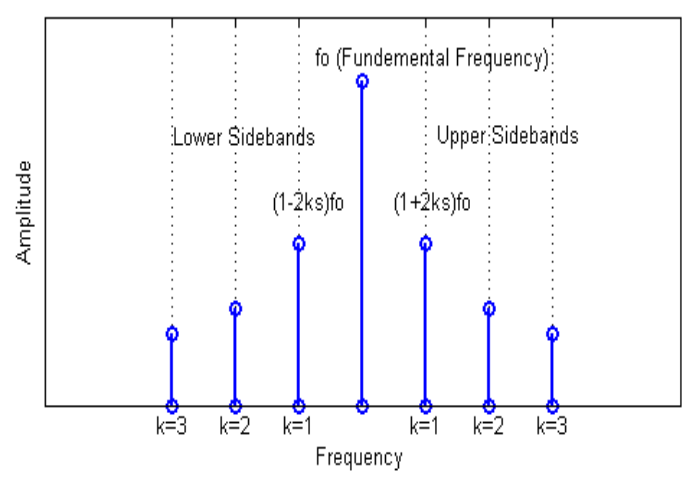

Fig.2. Fundamental and sideband frequencies.

$$
r_{r} \approx \frac{\left(2 N_{S}\right)^{2}}{N_{b} / 3} r_{b}
$$

The $r_{b}$ expression used in Equation (5) represents the rotor bar resistance. In this case, the one phase equivalent resistance for a rotor with $n_{b b}$ rotor bar faults has been given below.

$$
r_{r}^{*} \approx \frac{\left(2 N_{S}\right)^{2}}{\frac{N_{b}}{3}-3 n_{b b}} r_{b}
$$

$N_{s}$ represents the equivalent stator turn numbers of the winding. In this case, the change in the rotor phase resistances due to rotor bar faults, is defined by Equation (7).

$$
\Delta r=r_{r}^{*}-r_{r}=\frac{3 n_{b b}}{N_{b}-3 n_{b b}} r_{r}
$$

\section{RESAMPLING BASED ORDER TRACKING ANALYSIS METHOD}

The Order Tracking Analysis (OTA) method is one of the most frequently used methods for monitoring rotating machines. One of the biggest advantages of the OTA method when compared to other methods used in the analysis of vibration signals is that it provides successful results for non-stationary signals which vary in frequency and amplitude with the rotation of a shaft [19]. In the analysis of non-stationary signals, additional details are required according to the stationary signals to achieve successful results. The primary detail is the most accurate possible measurement of the motor speed information over the encoder. In recent years, many researchers have developed various methods for OTA. One of these methods is the Fourier Transformation Based Order Tracking (FFT-OT) method. However, this method is not successful enough for non-stationary signals and it is usually used to detect the order components in systems which have no or very small speed changes [20]. The second method is the RB-OTA method. With this method, many of the problems faced with the FFT-OT method were solved. This 
method is based on a resampling of the vibration signal according to the speed signal among the vibration and speed signals simultaneously monitored and recorded with a constant sampling speed [21]. The third method is the Vold Kalman Filter Based Tracking (VKF-OT) method. The primary difference between this method and the two methods mentioned above is a change in the amplitude and phase information of the signal [22]. Another method is the Gabor Order Tracking method based on the reconstruction principle of the wave form presented by Albriht and Qian in 2001 [23]. In this simulation and experimental study, the RB-OTA method was used as it provides successful results despite shorter processing times in real time applications. In addition, it is easily applied in terms of hardware. The most important difference distinguishing the presented study from other studies found in the literature is that it is applied to a non-stationary phase current rather than vibration signals.

In the RB-OTA method, the constant angular intervals are resampled with the constant sampling data. When sampled with constant $\Delta t$, the sampling data is transformed to equal angular intervals with the interpolation algorithm. The times where equal angular intervals are formed are calculated with the processing of the encoder signal. After resampling the data, the equivalence of the data in the time domain is decided [20]. This process can be realized in real time with special data acquisition hardware systems. The data transformed into the angular domain is processed according to the FFT or Discrete Fourier transformation [20]. The exit spectral lines represent constant orders as long as the transforms are performed on angular domain data. This means that there are equivalent sampling relations against the time/frequency sampling relations in the angle/order domain. These equivalent sampling relations are given in Equation (8).

$$
\begin{gathered}
\Delta_{0}=\frac{1}{R}=\frac{1}{N * \Delta \theta} \\
R=N * \Delta \theta
\end{gathered}
$$

$$
\begin{aligned}
O_{\text {nyqu it }}=O_{\text {max }} & =\frac{O_{\text {sam } p \boldsymbol{k}}}{2} \\
O_{\text {sam } p \boldsymbol{e}} & =\frac{1}{\Delta \theta}
\end{aligned}
$$

$\Delta_{0}$ used in Equation 8 represents the order resolution of the output order spectrum, $R$ represents the total number of analyzed values, $N$ represents the total number of points on the realized transformations, $\Delta \theta$ represents the angular spacing of the repeated samples, $O_{\text {sampe }}$ represents the angular sample rate with which the data is sampled, $O_{\text {nyquit }}$ represents the Nyquist order and $O_{\max }$ represents the maximum sample which can be analyzed. This means that the analysis for good order resolution should be applied to many resolutions. The maximum order which can be analyzed can be found with the corresponding number of samples or the angular sampling rate per revolution. The angular size of the cores of the transformations is given in Equation (9) [20].

$$
\begin{aligned}
& a_{m}=\frac{1}{N} \sum_{n=1}^{N} x(n \Delta \theta) \cos \left(2 \pi o_{m} n \Delta \theta\right) \\
& b_{m}=\frac{1}{N} \sum_{n=1}^{N} x(n \Delta \theta) \sin \left(2 \pi o_{m} n \Delta \theta\right)
\end{aligned}
$$

$o_{m}, a_{m}$ and $b_{m}$ the expressions given in Equation (9) represent, respectively, the order which is being analyzed, Fourier coefficient of the cosine term for $o_{m}$ and the Fourier coefficient for the sinus term for $o_{m}$.

\section{SIMULATION AND EXPERIMENTAL STUDY}

In this part, an induction motor with FOC has been modeled in Matlab/Simulink. In the prepared model 1, 2 and 3 BRB faults were simulated at various speeds and loads. The Simulink block diagram prepared for the FOC in an induction motor has been given in Fig. 3 [33].

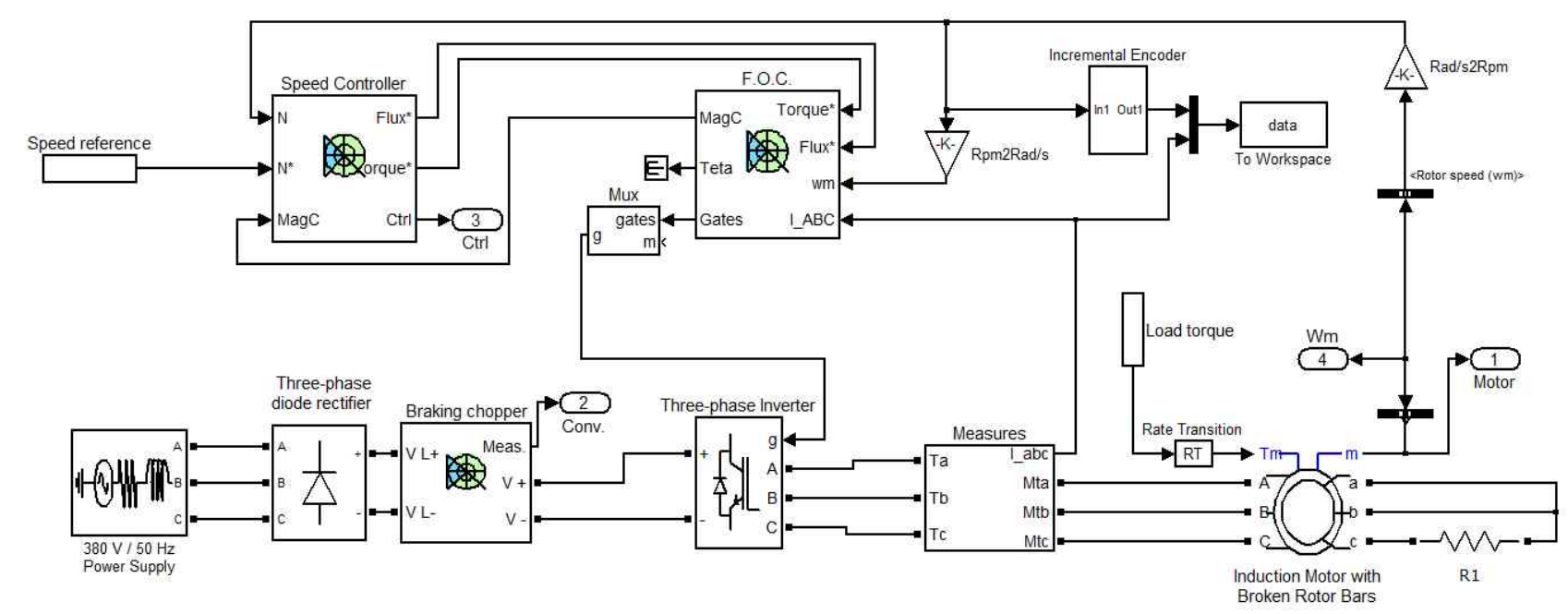

Fig. 3. Block diagram of the FOC of induction motor. 
TABLE I

PARAmeters OF The INdUCtion Motor Used

\begin{tabular}{lc}
\hline Rated power & $2238 \mathrm{~W}$ \\
Rated phase voltage & $220 \mathrm{~V}$ \\
Rated frequency & $50 \mathrm{~Hz}$ \\
Number of pole-pairs & 2 \\
Stator winding resistance & $0.435 \Omega$ \\
Stator winding inductance & $2 \mathrm{e}-3 \mathrm{H}$ \\
Rotor winding resistance & $0.816 \Omega$ \\
Rotor winding inductance & $2 \mathrm{e}-3 \mathrm{H}$ \\
Mutual inductance & $69.31 \mathrm{e}-3 \mathrm{H}$ \\
Moment of inertia & $0.089 \mathrm{~kg} \cdot \mathrm{m}^{2}$ \\
Friction factor & $0.005 \mathrm{Nms}$ \\
Number of rotor bars & 28 \\
\hline
\end{tabular}

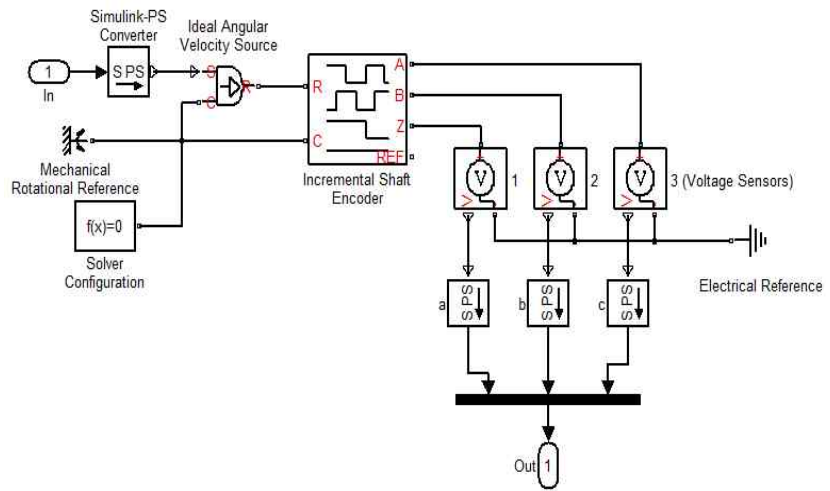

Fig. 4. The block diagram of the incremental encoder model used.

In the simulation and experimental studies a 4 pole induction motor with a shaft power of $2.2 \mathrm{~kW}$ was used. The parameters of the motor have been given in Table I.

In the simulation study, the motor current and rotor speed were recorded at a sampling rate of $50 \mathrm{kS} / \mathrm{s}$ after applying the reference speeds according to the predetermined run up, constant speed and run down ramps for 5 seconds. In the RB-OTA method used in this paper, the rotor speed should be defined as an incremental encoder output. To this end, a block that transforms the rotor speed to an encoder signal was modeled and coupled to the real model. The incremental encoder model formed generates $1 \mathrm{ppr}$ and $5 \mathrm{~V}$ output. A block diagram of the incremental encoder model has been given in Fig. 4.

In the Simulink model, BRB faults are realized by additional resistances added to the rotor circuit. The resistance values were calculated by using Equation (7). Accordingly, the resistance values that should be added in order to create 1, 2 and $3 \mathrm{BRB}$ faults are $\Delta r_{r 1}=0.0979 \Omega$, $\Delta r_{r 2}=0.2225 \Omega$ and $\Delta r_{r 3}=0.3865 \Omega$ respectively.

In the experimental study, a $2.2 \mathrm{~kW} 4$ pole star connected squirrel cage induction motor was used. The motor is loaded with an eddy current brake whose armature voltage and current are $48 \mathrm{~V} \mathrm{dc}$ and $2.2 \mathrm{~A}$, respectively. The squirrel cage induction motor was driven by a Siemens Sinamics CU 310 DP inverter. The purpose of motor monitoring system is to measure the motor stator current and rotor speed. The motor current and speed were measured by using a c-DAQ 9174 with a NI9227 current module, a NI9239 voltage module and both through an incremental encoder.

The RB-OTA was implemented by using NI Sound and Vibration Assistant software. The motor current and speed signals are acquired at a sampling rate of $50 \mathrm{kS} / \mathrm{s}$ for healthy and under $3 \mathrm{BRB}$ faults for no load and full load conditions. The motor test bench and faulty rotor are illustrated in Fig.5.

\section{APPLICATION FOR RESAMPLING BASED ORDER TRACKING ANALYSIS METHOD}

In this section, the FFT and RB-OTA transformations were implemented on the current signal obtained as a result of simulations and experimental study. The results obtained for both healthy and faulty conditions were compared. In both methods the Hanning window method was preferred. This window method is popular since it generates well balanced data due to the function used. As can be seen in Fig. 6, the run up, constant speed and run down regions were determined to be 0-1.5 s, 1.5-3.5 s and 3.5-5 s, respectively. When the run up and run down regions are examined it is observed that both the amplitude and the frequency of the currents change. FFT and RB-OTA transformations were made on the current signal obtained in these operating regions for no loaded and fully loaded cases for all 3 bar faults, and the frequency-order components related to the faults were examined in the spectrum graphs. The motor current and speed wave figures have been given in Fig. 6 .

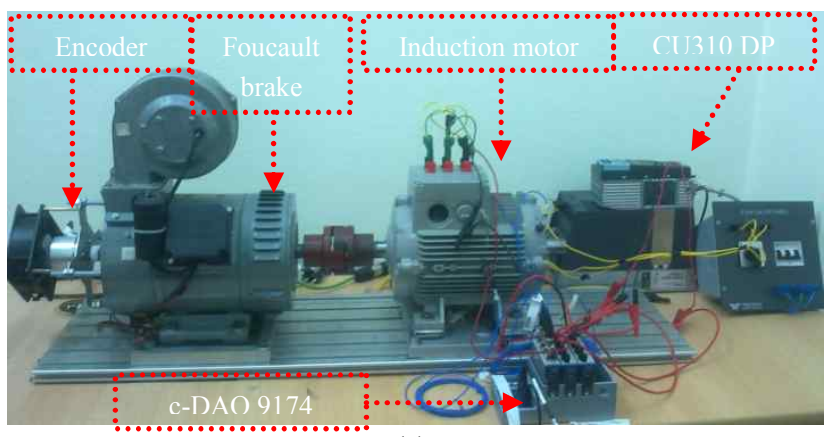

(a)

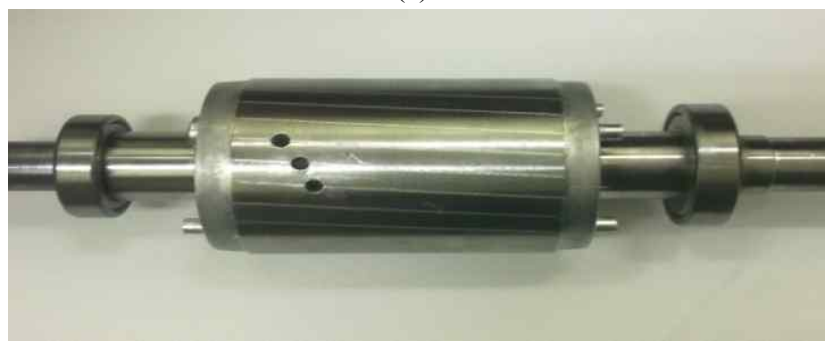

(b)

Fig. 5. (a) Experimental test rig, (b) Faulty rotor. 

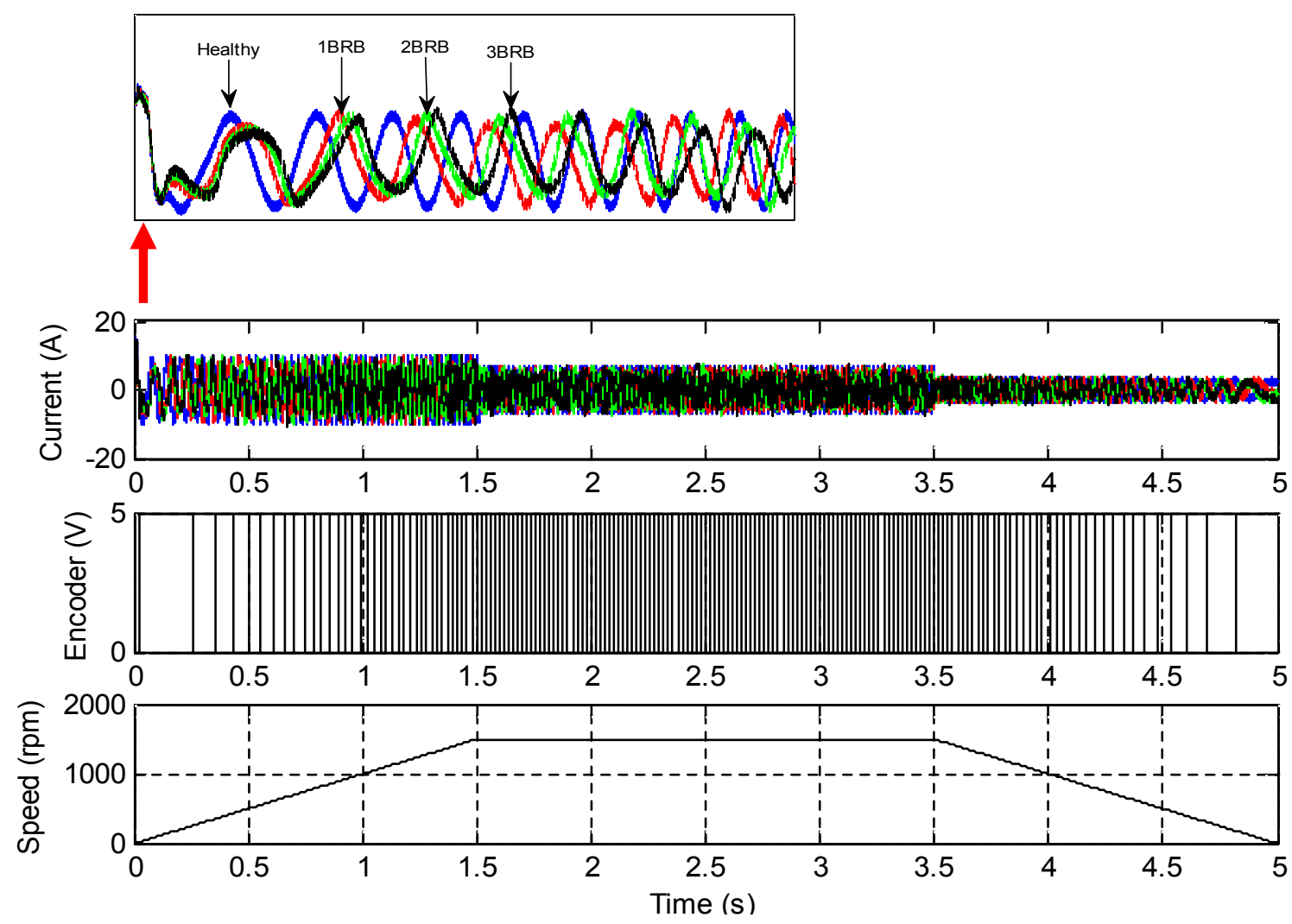

Fig. 6. Motor full load current speed graph(simulation).
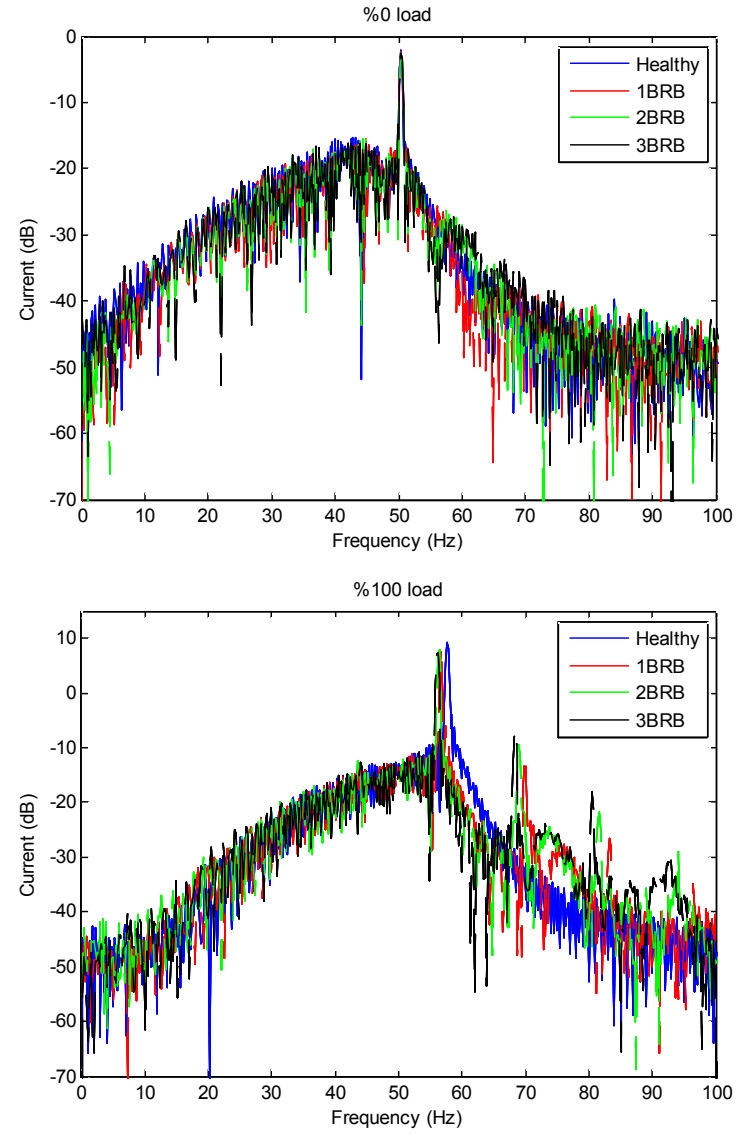

Fig. 7. Motor current FFT spectra (simulation).
When the no load motor operating spectrum graph is examined, it is seen that the fundamental frequency occurs at $50.4 \mathrm{~Hz}$. At this operating load the motor slip $(s)$ is 0.0079 . According to Equation (1), there should be frequency components at 49.6 $\mathrm{Hz}$ and $51.19 \mathrm{~Hz}$. However, as is the case in other studies in the literature, the determination of BRB faults via the FFT spectrum in unloaded operation is quite difficult. However, when the motor full load spectrum graph is examined the fundamental frequency is observed at $56.2 \mathrm{~Hz}$. Since the system operates in the closed loop speed control mode, the frequency of the motor current has increased in order to reach the desired output. In this operating load, the motor slip is 0.11. For the 3 BRB faults, the frequency components were observed in the upper sidebands of the fundamental frequency at $68.56 \mathrm{~Hz}$ and $80.92 \mathrm{~Hz}$. These components are frequency components formed due to oscillations in speed. However, the frequency components related to the BRB faults that should be observed to the lower sideband of the fundamental frequency at $43,84 \mathrm{~Hz}$ and $31,48 \mathrm{~Hz}$ were not observed. As can be seen in Fig. 7, the same thing goes for both the $1 \mathrm{BRB}$ and $2 \mathrm{BRB}$ faults.

When the RB-OTA method was applied to the current under the same operating conditions as for the 1, 2 and 3 BRB faults, the result were given in Fig. 8. 

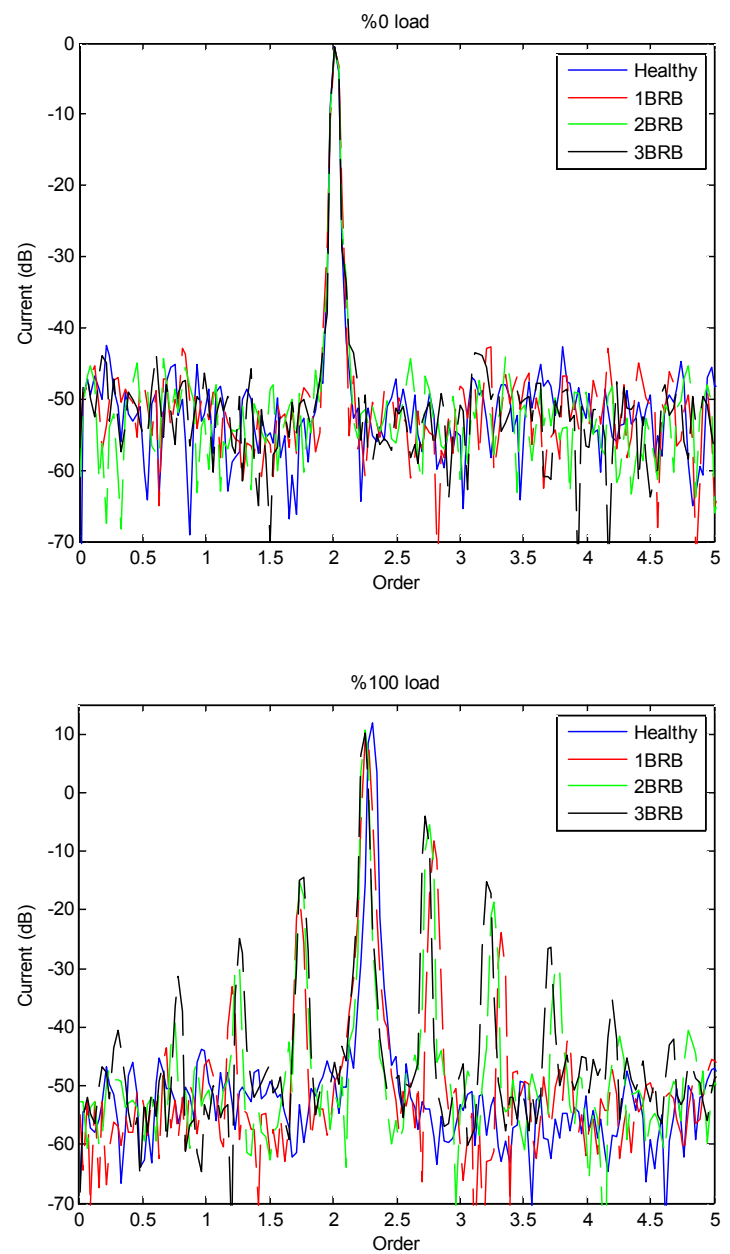

Fig. 8. Motor current RB-OTA spectra (simulation).

The location on the order spectrum of the frequency component in the frequency spectra is obtained by the equation Order $=$ Frequency $* \frac{60}{n_{r}}$. Correspondingly, the fundamental component was obtained at the $2.01^{\text {st }}$ order in the unloaded operating spectrum and at the $2.24^{\text {th }}$ order in the fully loaded operation. In the unloaded operation no fault component was observed as was the case in the FFT spectrum. However, when the full load spectrum is examined, order components are observed both to the upper and lower regions of the fundamental component. The component on the lower sideband was observed at the $1.75^{\text {th }}$ order whereas the component on the upper sideband was observed at the $2.72^{\text {nd }}$ order. Again, in accordance with the $k$ expression in Equation (1), the sidebands related to the faults and the oscillations in speed are clearly observed in the order spectrum. As can be observed from the graphical results, the RB-OTA method is very effective in determining faults in dynamic operating conditions. Hence the order component, the place on the lower sideband which changes according to $(1-2 s) f$ will give accurate information regarding BRB faults. The change in the amplitude values of this order component according to the load and the number of faulty rotor bars has been given in Fig. 9.

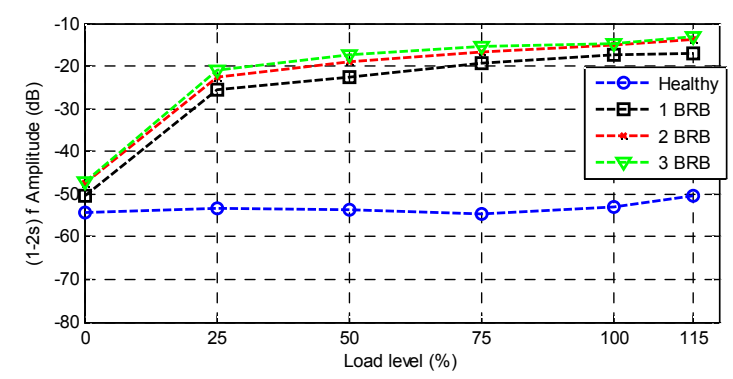

Fig. 9. The effect of increasing number of broken bar and load level on the amplitude of (1-2s) f component in order spectrum.
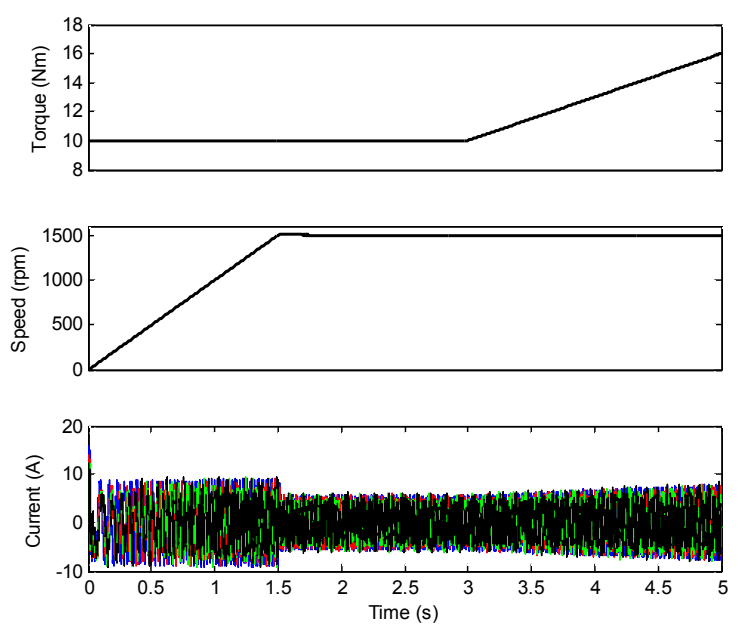

Fig. 10. The torque, speed and current graphs for a motor operating under variable load (simulation).

It can be easily observed from Fig. 9 that BRB faults are very difficult to determine in unloaded operating conditions and that there is an increase of about $25 \mathrm{~dB}$ in the amplitude of the related order component with load. In addition, the amplitude change increases with an increase in the number of breaks in the rotor bar at the same load amount.

The loads used in industry are mostly dynamic. While a change in the load causes a change in the motor speeds in line fed motors, it causes a change in the frequency and amplitude in inverter driven motors if closed loop speed control is in effect. The load of a motor operating under a $10 \mathrm{Nm}$ load is increased in the $3^{\text {rd }}$ second, thus increasing it to $110 \%$ of its nominal load. In this case the graphs for the obtained load, speed and current are given in Fig. 10.

As can be seen from the graph, with a load increase at the $3^{\text {rd }}$ second, both the amplitude and the frequency of the current drawn from the motor coils have increased.

The FFT and order spectra obtained in this case are given in Figs. 11 and 12, respectively. 


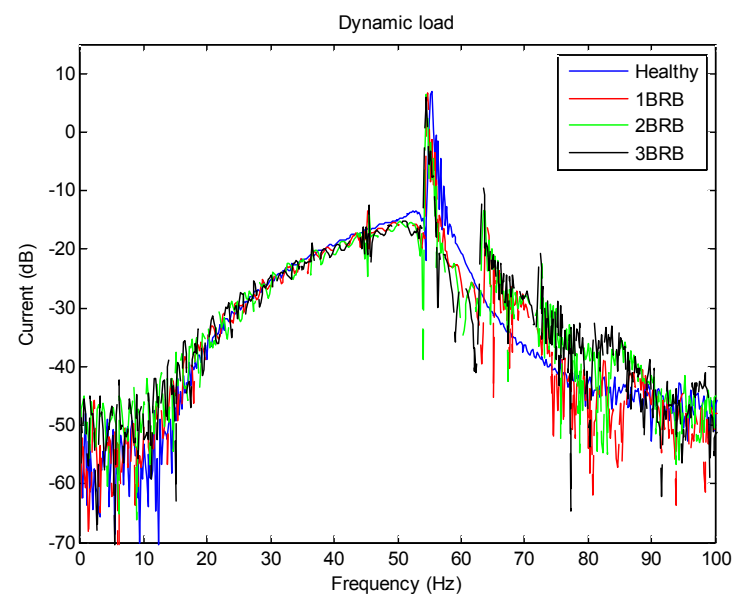

Fig. 11. FFT spectra of the motor operating under variable load (simulation)

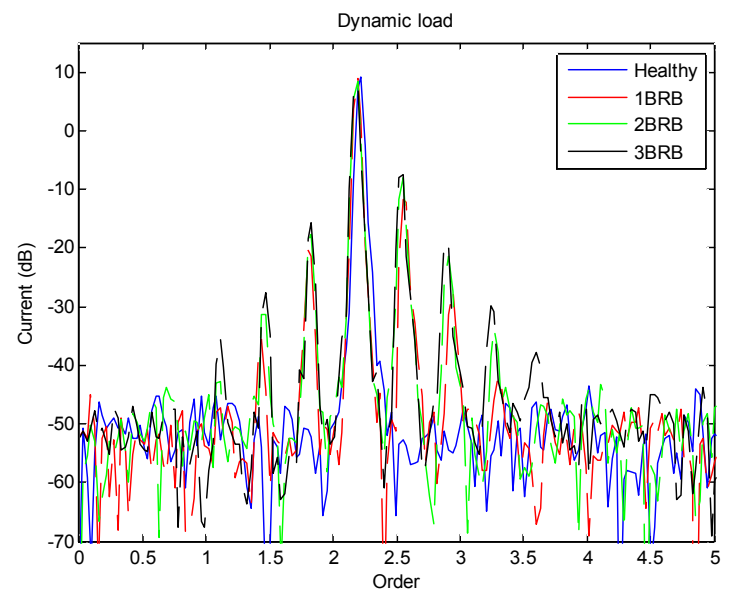

Fig. 12. RB-OTA spectra of the motor operating under variable load (simulation)

Whereas no fault related finding was observed in the FFT spectra as a result of the changes in the amplitude and frequency with the change in load, order components related to the fault are clearly observed in the upper and lower regions of the fundamental component in the order spectrum.

An experimental study was conducted in addition to the simulation study in order to show the effectiveness of the proposed method in determining BRB faults. In the experimental study, an induction motor was operated according to the velocity curve described in Fig. 6 at no load and full load conditions. The current FFT and order spectrums for healthy and $3 \mathrm{BRB}$ fault conditions were compared. A no load and full load FFT graph was displayed in Fig. 13 for the current condition of $3 \mathrm{BRB}$ faults. When examining the graph, it can be seen that there are no components related to the fault on the lower or the upper regions of the basic frequency. The RB-OTA method was implemented on the current signals recorded during the experimental study, and the obtained order spectrums are presented in Figs. 14 and 15.

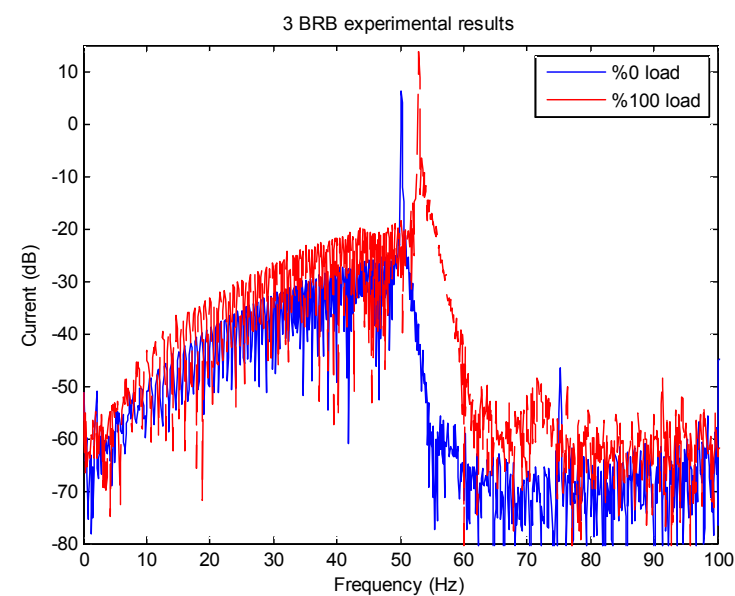

Fig. 13. Motor experimental current FFT spectra

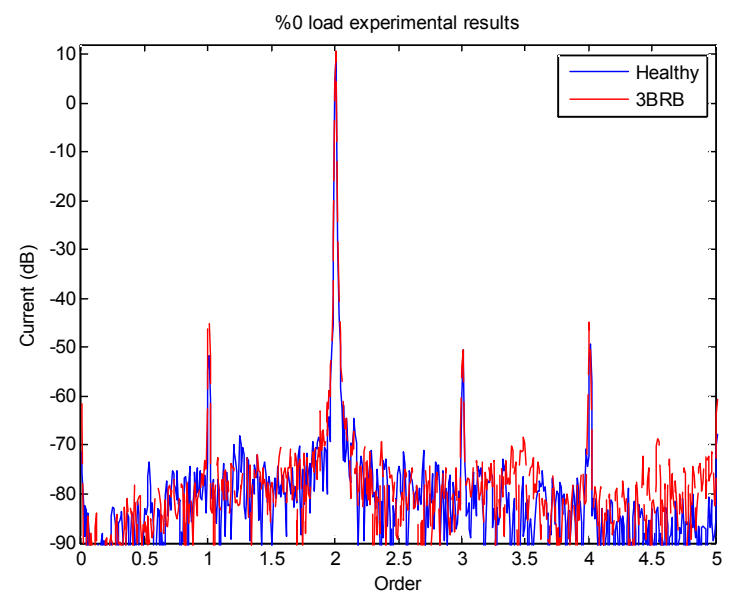

Fig. 14. Motor experimental current no load RB-OTA spectra

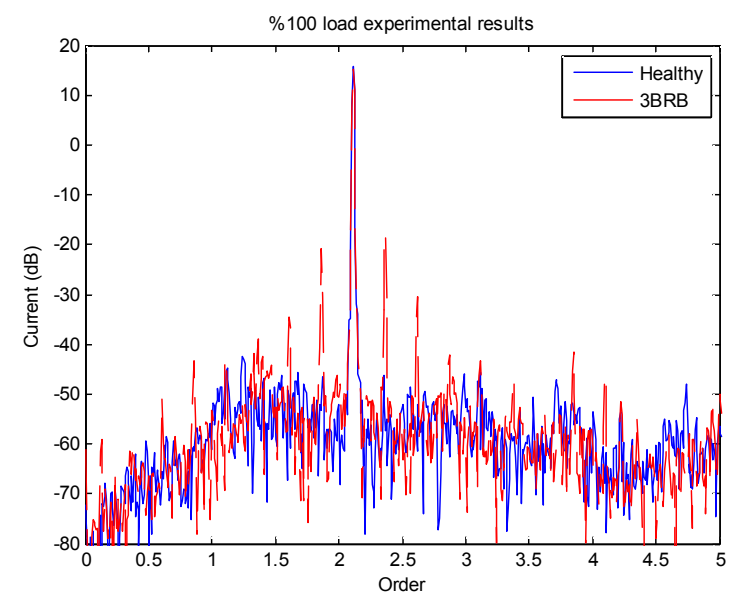

Fig. 15. Motor experimental current full load RB-OTA spectra

As in the simulation study, order components related to the fault were not found in this study. Misalignment peaks were detected at 1 . and 3 . order levels.

When the motor was loaded, as it operated in the closed loop speed control mode, the value of the supplying frequency increased; and it skipped into the 2.11 order level from the 2 . 
order level depending on the load amount. According to Equation 1, order components were found on the upper sidebands of the fundamental component at the 2.36 and 2.61 order levels and on the lower sidebands at the 1.86 and 1.60 order levels because of the BRB faults. The results obtained from the experimental study support the simulation study.

\section{CONCLUSIONS}

In the simulation and experimental study, BRB fault detection was carried out for inverter driven FOC controlled induction motors. The following results were obtained:

- Both the frequency and the amplitude of the current drawn by the motor change in the run up and run down regions. As a result of the analyses carried out in these regions it was determined that the FFT method contains no information regarding the faults. However, the RB-OTA method causes the signal in these regions to be stationary in the angular domain since it resamples the current according to the speed. Thus the order spectra obtained from these regions contain accurate information about the faults.

- In the study carried out for changes in the faults due to the load quantity and the number of broken bars, the results are similar to those in the literature which were obtained for motors operating in stationary conditions. The amplitude of the component to the lower of the fundamental component that gives information about faults increases in direct proportion to the load and the number of broken bars.

- When the load of a motor operating under a certain load at a constant speed is increased, both the amplitude and the frequency of the current increase. In this case, the FFT is insufficient in the analyses studies carried out whereas the RB-OTA method contains accurate information about the faults.

- The obtained experimental results support the simulation results and it has shown that the method will successfully detect BRB faults in inverter-driven motors.

- One of the biggest advantages of the presented method is that it involves no additional cost for the user, because there are built in current and speed sensors in inverter driven systems. The inverter can be made to attain the abilities of online motor monitoring and fault detection in addition to its driver ability via additional software without any extra hardware requirements. Thus the maintenance costs of facilities can be lowered while their security is enhanced.

\section{ACKNOWLEDGEMENT}

This study was supported by the Gaziosmanpaşa University Scientific Research Projects Foundation under Grant No. 2011/04

\section{REFERENCES}

[1] M. Akar and I. Cankaya, "Broken rotor bars fault detection in inverter fed squirrel cage induction motors by using stator current analysis and fuzzy logic," Turkish Journal of Electrical Engineering and Computer Sciences, Vol. 20, No. 1, pp. 1077-1089, 2012.

[2] S. Seker, "Determination of air-gap eccentricity in electric motors using coherence analysis," IEEE Power Engineering Review, Vol. 20, No. 7, pp. 48-50, Jul. 2000.

[3] S. Seker and E. Ayaz, "A reliability model for induction motor ball bearing degradation," Electric Power Components \& Systems, Vol. 31, No. 7, pp. 639-52, Jul. 2003.

[4] E. Ayaz, S. Seker, and A. Ozturk, "Continuous wavelet transform for bearing damage detection in electric motors," in Proceeding of IEEE Melecon, pp. 1130-1133, Spain, 2006

[5] E. Ayaz, S. Seker, A. Ozturk, and B. R. Upadhyaya, "Fault detection based on continuous wavelet transform and sensor fusion in electric motors," Compel, Vol. 28, No. 2, pp. 454-70, Mar. 2009.

[6] S. Nandi, H. A. Toliyat, and X. Li, "Condition monitoring and fault diagnosis of electrical motors - a review," IEEE Trans. Energy Convers., Vol. 20, No. 4, pp.719-729, Dec. 2005.

[7] S. Seker and E. B. Ayaz, "Feature extraction related to bearing damage in electric motors by wavelet analysis," Journal of the Franklin Institute, Vol. 340, No. 2, pp. 125 -134, Mar. 2003.

[8] I. Coskun and A. Saygin, "Speed control of induction motor by matrix converter," Gazi University Journal of Science, Vol. 17, No. 2, pp. 63-76, Mar. 2004.

[9] B. Akin, H. Toliyat, U. Orguner, and M. Rayner, "Low-cost motor drive-embedded fault diagnosis a simple harmonic analyzer," in Proceeding of APEC, pp. 243-249, U.S.A., 2007.

[10] R. R. Schoen, and T. G. Habetler, "Evaluation and implementation of a system to eliminate arbitrary load effects in current-based monitoring of induction machines," IEEE Trans. Ind. Appl., Vol. 33 No. 6, pp.1571-1577, Now. 1997

[11] W. T. Thomson, and M. Fenger, "Current signature analysis to detect induction motors faults," IEEE Industry Applications Magazine, Vol. 7 No. 4, pp. 26-34, Jul. 2001.

[12] C. Delmotte-Delforge, H. Hénao, G. Ekwe, P. Brochet, and G. A. Capolino, "Comparison of two modeling methods for induction machine study: application to diagnosis," Compel, Vol. 22 No. 4, pp.891-908, Dec. 2003.

[13] F. Filippetti, M. Martelli, G. Franceschini, and C. Tassoni, "Development of expert system knowledge base to on-line diagnosis of rotor electrical faults of induction motors," in Proceeding of IEEE IAS, Texas, USA, pp. 92-99, 1992.

[14] K P. olodziejek and E. Bogalecka, "Broken rotor bar impact on sensorless control of induction machine," Compel, Vol. 28, No. 3, pp.540-555, Now. 2009.

[15] A. Bellini, F. Fillippetti, G. Franceschini, C. Tassoni, and G. Kliman, "Quantitative evaluation of induction motor broken bars by means of electrical signature analysis," IEEE Trans. Ind. Appl., Vol. 37, No. 5, pp. 1248-1255, Sep. 2001.

[16] M. Moradian, M. Ebrahimi, M. Danesh, and M. bayat, "Detection of broken bars in induction motors using a 
neural network," Journal of Power Electronics, Vol. 6, No. 4, pp. 245-252, Jul. 2006.

[17] J. H. Jung, "Oxidation models of rotor bar and end ring segment to simulate induction motor faults in progress," Journal of Power Electronics, Vol. 11, No. 2, pp. 163-172, Mar. 2011.

[18] N. H. Kim, W. S. Baik, M. H. Kim, and C.H. Choi, "Rotor fault detection system for the inverter driven induction motor using current signals," Journal of Power Electronics, Vol. 9, No. 2, pp. 224-231, Mar. 2009.

[19] National Instruments, Sound and Vibration Measurement Suite 2009 Help Manual, part number 372416C-01, Jun. 2009.

[20] J. R. Blough, "Development and analysis of time variant discrete fourier transform order tracking," Mechanical Systems and Signal Processing, Vol. 17, No. 6, pp.1185-1199, Nov. 2003.

[21] K. R. Fyfe and D. S. Munck, "Analysis of computed order tracking," Mechanical Systems and Signal Processing, Vol. 11, No. 2, pp. 187-205, Mar. 1997.

[22] H. Vold, H. Herlufson, M. Mains, R. D. Corwin, "Multi axle order tracking with the vold-kalman tracking filter," Sound and Vibration Magazine, Vol. 13, No. 5, pp. 30-34, 1997

[23] M .F. Albright and S. Qian, "A comparison of the newly proposed gabor order tracking technique vs. other order tracking methods," in Proceeding of SAE, No. 2001-01-1471, Apr. 2001.

[24] N. Mehala and R. Dahiya, "Rotor faults detection in induction motor by wavelet analysis," International Journal of Engineering Science and Technology, Vol.1, No. 3, pp. 90-99, Mar. 2009.

[25] H Calis and A Cakir, "Rotor bar fault diagnosis in three phase induction motors by monitoring fluctuations of motor current zero crossing instants," Electric Power System Research, Vol. 85, No.5, pp.385-392, Apr. 2006.

[26] W. T. Thomson and I. D. Stewart, "On-line current monitoring for fault diagnosis in inverter fed induction motors," in Proceeding of $3^{\text {rd }}$ Int. Conf. Power Electronics Drives, pp. 432-435, 1988.

[27] G. B. Kliman, R. A. Koegl, J. Stein, R. D. Endicott, and M. W. Madden, "Noninvasive detection of broken rotor bars in operating induction motors," IEEE Trans. Energy Convers., Vol. 3, No. 4, pp. 873-879, Dec. 1988.

[28] F. Filippetti, G. Franceschini, C. Tassoni, and P. Vas, “Ai techniques in induction machines diagnosis including the speed ripple effect," in Proceeding of IEEE Industry Applications Soc. Annu. Meeting Conf., San Diego, CA, pp. 655-662, 1996.

[29] N. Elkasabgy, A. R. M. Eastham, and G. E. Dawson, "Detection of broken bars in the cage rotor on an induction machine," IEEE Trans. Ind. Appl., Vol. 22, No. 6, pp. 165-171, Jan. 1992.

[30] M. Haji and H. A. Toliyat, "Pattern recognition-a technique for induction machines rotor broken bar detection," IEEE Trans. Energy Convers., Vol. 16, No. 4, pp. 312-317, Dec. 2001.

[31] B. Ayhan, J. Trussell, and M. Y. Chow, "On the use of a lower sampling rate for broken rotor bar detection with $\mathrm{dtft}$ and ar-based spectrum methods," IEEE Transaction on Industrial Electronics, Vol. 55, No. 3, pp.1421-1434, Mar. 2008 .
[32] S. Chen, and R. Zivanovic, "Modeling and simulation of stator and rotor fault conditions in induction machines for testing fault diagnostic techniques," European Transactions on Electrical Power, Vol. 20, No. 5,pp.611-629, Apr. 2009.

[33] Matlab 2011a, Simpower Systems User's guide, 2011.

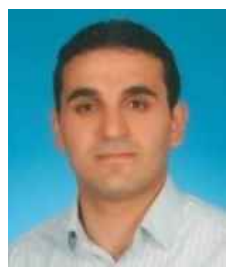

Mehmet Akar was born in Tokat, Turkey, in 1979. He received his B.S. and M.S. in Electrical Education from the University of the Marmara, Istanbul, Turkey, in 2002 and 2005, respectively, and his Ph.D. in Electronic and Computer Education from Sakarya University, Sakarya, Turkey, in 2009. He is currently working as an Assistant Professor in the Mechatronics Engineering Department, Gaziosmanpasa University, Tokat, Turkey. His current research interests include condition monitoring techniques of electrical machines and signal processing. 